\title{
Bronchial temperature reflects transcapillary heat transport of isolated blood-perfused rabbit lungs
}

\author{
S.A. Loer, J.O. Arndt
}

Bronchial temperature reflects transcapillary heat transport of isolated blood-perfused rabbit lungs. S.A. Loer, J.O. Arndt. (OERS Journals Ltd 1998.

ABSTRACT: The pulmonary capillaries are in such close proximity to the terminal airways that changes in capillary blood temperature should also cause changes in bronchial wall temperature. Therefore, we hypothesized that injection of cold solutions into the pulmonary artery would yield bronchial temperature-time curves similar to those in the pulmonary artery and left atrium. These bronchial curves should mainly represent the capillary bed.

Isolated rabbit lungs $(\mathrm{n}=8)$ were ventilated $\left(5 \% \mathrm{CO}_{2}\right.$ in air) and perfused (autologous blood, $37^{\circ} \mathrm{C}$ ) at various flow rates $\left(50-200 \mathrm{~mL} \cdot \mathrm{min}^{-1}\right)$. Thermistor probes (diameter $0.46 \mathrm{~mm}$ ) registered temperature changes in the pulmonary artery, at the bronchial wall (wedge position) and in the left atrium after injection of $0.8 \mathrm{~mL}$ Ringer's lactate $\left(0^{\circ} \mathrm{C}\right)$ into the pulmonary artery.

Bronchial temperature-time curves were found to resemble "dilution" curves located between pulmonary arterial and left atrial curves. Independent of flow rate, their appearance times, peaks and calculated mean transit times were between those from the pulmonary artery and the left atrium.

We conclude that bronchial temperature-time curves reflect transcapillary heat transport and that this approach might be useful in gaining further information about vascular transport processes in the interior of the lung. Eur Respir J 1998; 11: 334-338.

The terminal airways are separated from the surrounding pulmonary capillaries by a tissue layer only a few micrometers thick. Therefore, they could be interesting targets for gaining information about transcapillary heat transport. Their particular anatomy should favour a rapid equilibration of heat diffusion between the capillary bed and the distal bronchial walls, especially since significant indicator transfer to the intrabronchial space after injection of cold solutions into the pulmonary artery has been observed [1]. Therefore, it should be possible to trace temperature changes of the capillary blood by recording bronchial temperature. These temperature-time curves after injection of cold solutions into the pulmonary artery should allow calculation of mean transit times from the pulmonary artery to the bronchial system and from there to the left heart and, thus, provide information about transcapillary transport in the interior of the lung.

To study this new approach under controlled experimental conditions, we recorded thermodilution curves in the pulmonary artery, at the wall of small bronchioles and in the left atrium of isolated rabbit lungs perfused with their own blood. This experimental procedure allowed a huge range of alterations to be made to pulmonary blood flow as the major variable for pulmonary mean transit times.

\section{Materials and methods}

\section{Animals and isolation of the lungs}

Temperature-time curves were recorded at the wall of small bronchioles, in the pulmonary artery and in the left
Institut für Experimentelle Anaesthesiologie, Heinrich-Heine-Universität Düsseldorf, Germany

Correspondence: S.A. Loer

Institut für Klinische Anaesthesiologie,

Geb. 12.42,

Heinrich-Heine-Universität Düsseldorf

Moorenstraße 5

D-40225 Düsseldorf

Germany

Fax: 49211816253

Keywords: Bronchial temperature isolated rabbit lungs

precapillary and postcapillary mean transit times

thermodilution

Received: March 111997

Accepted after revision October 211997 atrium of isolated lungs of New Zealand white rabbits treated in accordance with the Helsinki convention for the use and care of animals and with approval of the governmental animal care and use commission. Adult rabbits (mean $( \pm \mathrm{SD})$ body weight $3.3 \pm 0.3 \mathrm{~kg}$ ) of either sex were anaesthetized with pentobarbital sodium $\left(30 \mathrm{mg} \cdot \mathrm{kg}^{-1} i . v\right.$. $)$. After tracheotomy, the animals' lungs were mechanically ventilated with air at a tidal volume $(V \mathrm{~T})$ of $10 \mathrm{~mL} \cdot \mathrm{kg}^{-1}$ and a frequency of 30 breaths. $\mathrm{min}^{-1}$ (Harvard Respirator, model 683; Harvard Apparatus, South Natick, MA, USA). Heparin $\left(1,000 \mathrm{IU} \cdot \mathrm{kg}^{-1}\right)$ was injected $3 \mathrm{~min}$ before the rabbits were exsanguinated through the carotid artery. After midline sternotomy, the trachea, heart and lungs were removed en bloc and perfusion cannulas tied into the pulmonary artery and left atrium via the left ventricle with meticulous care to avoid air embolism. These cannulas had separate lumina allowing pressure as well as temperature (thermistor) measurements at their tips. The pulmonary arterial catheter had an additional injection port $1.8 \mathrm{~cm}$ proximal to the thermistor for the injection of the tracer. The rabbits' own blood was used to fill the extracorporeal perfusion circuit with a capacity of $35 \mathrm{~mL}$.

The time from excision of the lungs to the start of the in vitro perfusion was less than $12 \mathrm{~min}$. The lungs were suspended via the trachea from a force transducer and inflated up to $15 \mathrm{cmH}_{2} \mathrm{O}$ until any visible atelectasis had resolved. Thereafter, the lungs were covered with a thin plastic foil to conserve heat and humidity, and were ventilated $\left(V \mathrm{~T}\right.$ of $10 \mathrm{~mL} \cdot \mathrm{kg}^{-1}$, respiratory frequency $(f \mathrm{R})$ of 30 breaths $\cdot \min ^{-1}$ ) with $5 \% \mathrm{CO}_{2}$ in air. An end-expiratory 
pressure of $2 \mathrm{cmH}_{2} \mathrm{O}$ was maintained in the expiratory limb of the ventilation circuit by an underwater seal.

The lungs were perfused at constant flow by a roller pump (Model 16670; American Optical Corporation, Bedford, MA, USA) calibrated by timed collections prior to and after each experiment. The temperature of the perfusate was maintained at $37^{\circ} \mathrm{C}$ with a water bath, and $\mathrm{pH}$ was kept in the range $7.30-7.45$ by addition of sodium bicarbonate when necessary.

\section{Measurements}

Temperatures in the pulmonary artery, left atrium and bronchial system were measured with thermistor probes (BetaTherm, Shrewsbury, MA, USA) connected to a Wheatstone bridge, with the following characteristics: diameter $0.46 \mathrm{~mm}$; resistance at $20^{\circ} \mathrm{C}\left(R 20^{\circ} \mathrm{C}\right)=20 \mathrm{k} \Omega$, dissipation constant $0.08 \mathrm{~mW}$ (worst case); and $90 \%$ response time $(t 90 \%)$ in water $70 \mathrm{~ms}$.

The thermistor probes were placed just downstream of the orifice of the inflow cannula in the pulmonary artery and upstream of the orifice of the outflow cannula in the left atrium. The bronchial thermistor was introduced through the trachea and wedged into its final position so that it contacted a bronchiole with a diameter of about $0.46 \mathrm{~mm}$, i.e., the size of the thermistor probes.

Pressures in the pulmonary artery, left atrium and trachea were measured continuously with electromanometers (Statham P23 ID, Oxnard, CA, USA) relative to atmospheric pressure. The apex of the suspended lung was chosen as the reference level for all pressures.

The weight of the lung was measured continuously with a force transducer (Model FTO3; Grass Instruments, Quincy, MA, USA) allowing changes of less than $0.1 \mathrm{~g}$ to be recorded.

The haematocrit of the perfusate was determined at the beginning and the end of the experiments to exclude relevant changes of red blood cell concentration (Haematokrit-Zentrifuge, Hettich, Germany). Except for haematocrit, all variables were recorded continuously on a chart (Astro-med, Rodgau, Germany).

\section{Programme of experimentation}

The perfused lungs were initially observed for $20 \mathrm{~min}$ to establish an isogravimetric state with a pulmonary artery pressure between 15 and $20 \mathrm{cmH}_{2} \mathrm{O}$. To attain zone 3 flow conditions throughout the experiments and to minimize recruitment of unperfused lung regions during an increase of pulmonary arterial pressure, left atrial pressure was adjusted above airway pressure to $4 \mathrm{cmH}_{2} \mathrm{O}$ by the height of the venous reservoir at the beginning of the experiments at a flow rate of $50 \mathrm{~mL} \cdot \mathrm{min}^{-1}$.

Temperature-time curves were recorded after injection of ice-cold Ringer's lactate (always $0.8 \mathrm{~mL}$ ) by hand into the pulmonary artery over the injection port of the pulmonary arterial cannula. To ensure proper mixing of the injectate with the blood stream the cold solution was injected against the blood stream.

Flow rate varied between $50-200 \mathrm{~mL} \cdot \mathrm{min}^{-1}$, keeping a given flow constant for 20-40 min. Injections were repeated three times at intervals of $5 \mathrm{~min}$. Experiments were completed within 150 min of ex situ perfusion. All lungs exhibited stable filtration characteristics, indicated by negligible weight gain during the experiments. Haematocrit for initial perfusion was 33\% and decreased to $31 \%$ at the end of the experiments, the partial pressure of oxygen $\left(\mathrm{PO}_{2}\right)$ in the perfusate was always above $13.3 \mathrm{kPa}(100$ $\mathrm{mmHg})$, and partial pressure of carbon dioxide $\left(\mathrm{PCO}_{2}\right)$ within $4.7-6.0 \mathrm{kPa}(35-45 \mathrm{mmHg})$. Lungs with changes in vascular pressures, especially with increases in pulmonary arterial pressure above $30 \mathrm{cmH}_{2} \mathrm{O}$, were not used in this study.

\section{Analysis}

The temperature-time curves were digitized from the time of injection until the curves returned to within $5 \%$ of baseline. The mean transit times $(\bar{t})$ from the injection site to the pulmonary artery ( $\left.\bar{t}_{\mathrm{pa}}\right)$, the bronchial system $(\bar{t} \mathrm{br})$ and the left atrium ( $\bar{t}$ la) was calculated from:

$$
\bar{t}=1 / 2 t \cdot \Delta T \cdot \mathrm{d} t / 1 / 2 \Delta T \cdot \mathrm{d} t
$$

where $\Delta T=$ amplitude of the recorded change in temperature at $0.1 \mathrm{~s}$ intervals and $t=$ time.

Mean transit times from injection to the respective recording site are presented as mean \pm SD. Paired t-tests were used to look for differences between mean transit times from the pulmonary artery to the bronchial site ( $\left.\bar{t} \mathrm{br}-\bar{t}_{\mathrm{pa}}\right)$ and from there to the left atrium ( $\bar{t} \mathrm{la}-\bar{t} \mathrm{br})$ for all experiments, as well as to look for differences of total pulmonary mean transit times between flow rates. An alpha adjusted p-value of less than 0.05 was considered statistically significant.

\section{Results}

The temperature-time curves recorded in the pulmonary artery, the bronchial site and the left atrium of the isolated lungs were similar, apart from the expected dispersion as the tracer passed the recording sites. Most important, however, was that bronchial curves resembled dilution curves and were always intermediate between those recorded in the pulmonary artery and left atrium. These principal observations are shown in figure 1 . In detail, there was an increasing delay in appearance times, times to peak and mean transit times as the tracer passed the three recording sites. In common with the pulmonary arterial and left atrial curves, the bronchial curve displayed a rapid increase and an exponential decay and returned to baseline. The bronchial appearance times, indicating arrival of the fastest particles, were intermediate between those recorded in the pulmonary artery and the left atrium. It is also apparent from figure 1 that mean transit times to the three locations decreased as blood flow increased from 50 to $200 \mathrm{~mL} \cdot \mathrm{min}^{-1}$. However, regardless of blood flow, the relative mean transit times (vertical lines) were by and large equal from the pulmonary artery to the bronchial site on the one hand, and from there to the left atrium on the other. The three curves were reproducible. When three repeated injections were performed under the same flow conditions the calculated mean transit times differed by less than $9 \%$. 

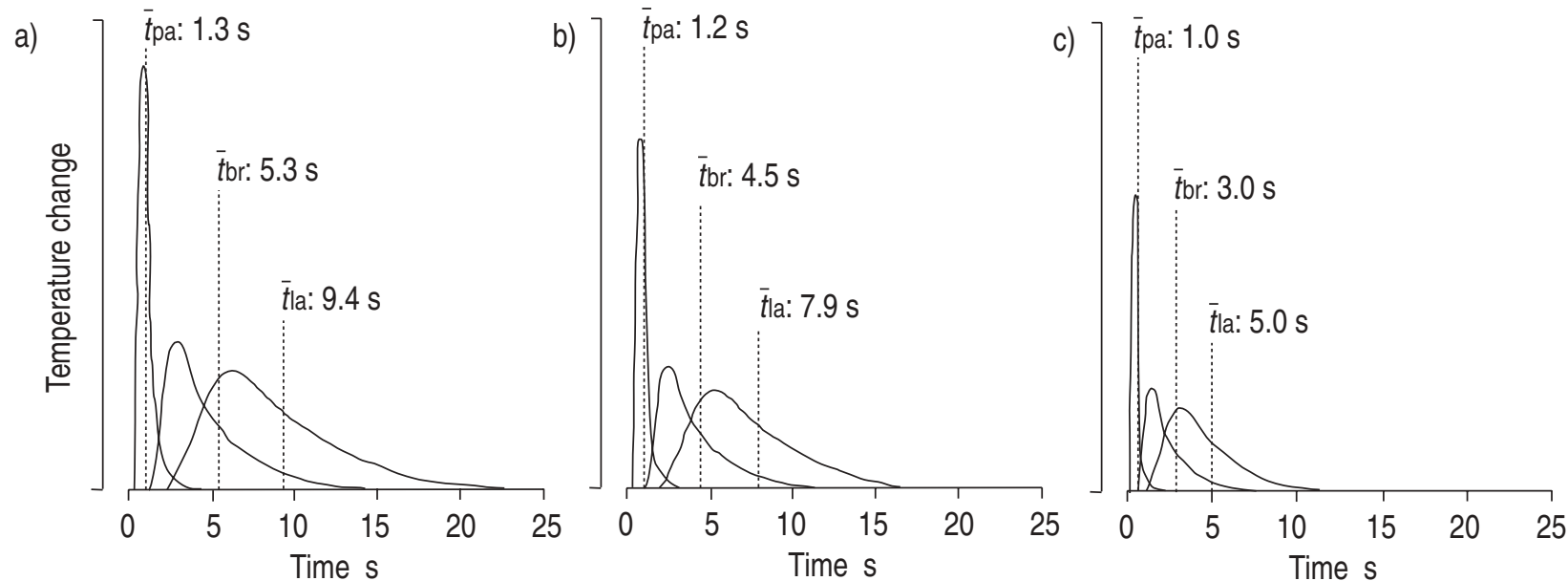

Fig. 1. - Original registrations of signals recorded in one lung after injection of $0.8 \mathrm{~mL}$ cold Ringer's solution demonstrating the effects of different flow rates: a) 50; b) 100 ; and c) $200 \mathrm{~mL} \cdot \mathrm{min}^{-1}$ on temperature time curves and mean transit times. The first peak represents the pulmonary artery, the second the bronchial system and the third the left atrium. The location of the bronchial curve as well as the mean transit times are between those attained in the pulmonary artery and left atrium. It peaks rapidly and then follows an exponential decay returning to baseline, irrespective of flow rate. Temperature signals in the bronchial system and the left atrium were amplified twofold. $\bar{t}_{\text {pa: }}$ transit time of the pulmonary artery; $\bar{t}$ br: transit time of the bronchial system; $\bar{t}$ a: transit time of the left atrium.

Table 1. - Pulmonary artery pressure $(P$ pa), thermal volume $(V$ th), appearance time, time to peak and mean transit time from time of injection for the pulmonary artery, bronchial system and left atrium

\begin{tabular}{|c|c|c|c|c|c|c|c|c|c|c|c|}
\hline \multirow[b]{2}{*}{$\begin{array}{c}\text { Flow } \\
\mathrm{mL} \cdot \mathrm{min}^{-1}\end{array}$} & \multirow[b]{2}{*}{$\begin{array}{c}P_{\mathrm{pa}} \\
\mathrm{cmH}_{2} \mathrm{O}\end{array}$} & \multirow[b]{2}{*}{$\begin{array}{l}V_{\text {th }} \\
\mathrm{mL}\end{array}$} & \multicolumn{3}{|c|}{ Pulmonary artery } & \multicolumn{3}{|c|}{ Bronchial system } & \multicolumn{3}{|c|}{ Left atrium } \\
\hline & & & $\begin{array}{l}\text { Appear- } \\
\text { ance } \\
\text { time } s\end{array}$ & $\begin{array}{c}\text { Time to } \\
\text { peak } \\
\mathrm{s}\end{array}$ & $\begin{array}{l}\text { Mean } \\
\text { transit } \\
\text { time } s\end{array}$ & $\begin{array}{l}\text { Appear- } \\
\text { ance } \\
\text { time } \mathrm{s}\end{array}$ & $\begin{array}{c}\text { Time to } \\
\text { peak } \\
\mathrm{s}\end{array}$ & $\begin{array}{l}\text { Mean } \\
\text { transit } \\
\text { time } s\end{array}$ & $\begin{array}{l}\text { Appear- } \\
\text { ance time } \\
\mathrm{s}\end{array}$ & $\begin{array}{c}\text { Time to } \\
\text { peak } \\
\mathrm{s}\end{array}$ & $\begin{array}{l}\text { Mean } \\
\text { transit } \\
\text { time } s\end{array}$ \\
\hline 5 & & & $<1.0$ & $11+03$ & $12=$ & $1.0-2.0$ & $3.4 \pm 0.5$ & $5.9 \pm 1.8$ & 2 & $7.3 \pm 0.5$ & 11. \\
\hline 10 & & & & & & $1.0-1.5$ & & & & & \\
\hline 200 & $25.3 \pm 2.2$ & $13.1 \pm 2.9$ & $<1.0$ & $0.6 \pm 0.1$ & $0.9 \pm 0.5$ & $<1.0$ & $2.0 \pm 0.4$ & $3.0 \pm 0.8$ & $1.5-2.0$ & $3.3 \pm 0.6$ & $4.8 \pm 1.1$ \\
\hline
\end{tabular}

Data are means ( \pm SD) from eight isolated rabbit lungs. Values of $V$ th were calculated as the product of flow and transpulmonary transit times (left atrial-pulmonary arterial times).

Similar results were obtained in all other experiments as summarized in table 1. In all eight lungs, appearance times, times to peak and mean transit times of the three curves (pulmonary artery, bronchiole and left atrium) decreased as flow increased from 50 to $200 \mathrm{~mL} \cdot \mathrm{min}^{-1}$. At the same time, total thermal volume, calculated as the product of flow and transpulmonary mean transit time ( $\bar{t}$ la $-\bar{t}$ pa), increased from 8.2 to $13.1 \mathrm{~mL}$, as expected with the flow dependent increase in pulmonary blood volume. Most important, however, while total thermal volume increased and transpulmonary mean transit times decreased substan-

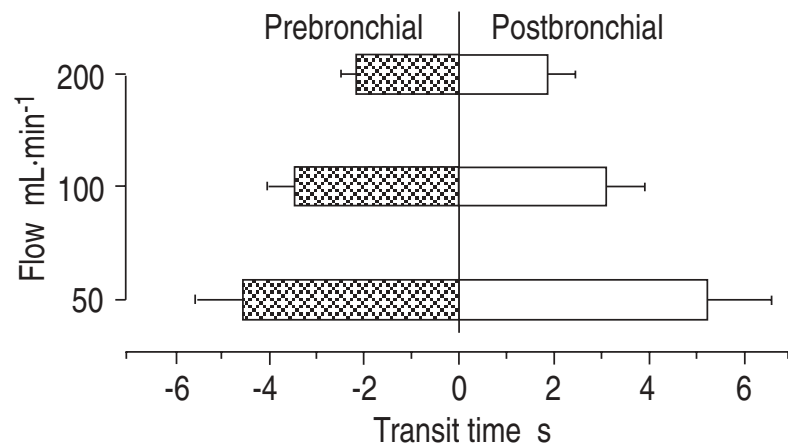

Fig. 2. - Effect of flow rate on calculated mean transit times. Data are presented as mean \pm S D of eight isolated perfused rabbit lungs. The transit times are presented with reference to the bronchial system $(0 \mathrm{~s})$. While total mean transit times decreased significantly, the ratio of preto postbronchial mean transit times did not change. $(\mathrm{p}<0.05$. tially as blood flow increased by a factor of four, there were no major alterations in the relation of pre- $\left(\bar{t} \mathrm{br}-\bar{t}_{\mathrm{pa}}\right)$ to postbronchial ( $\bar{t} \mathrm{la}-\overline{\mathrm{t}} \mathrm{br})$ transit times. With an increase in flow rate from 50 to $200 \mathrm{~mL} \cdot \mathrm{min}^{-1}$, prebronchial transit times decreased to $47 \%$ (from $4.6 \pm 1.0$ to $2.2 \pm 0.3 \mathrm{~s}$ ) and postbronchial transit times to $35 \%$ (from $5.22 \pm 1.2$ to $1.8 \pm$ $0.5 \mathrm{~s}$ ). This main finding is reflected in figure 2 showing the differences in the mean transit times with reference to that of the bronchial system for various blood flows.

\section{Discussion}

The recording of bronchial temperature-time curves together with those in the pulmonary artery and left atrium appears to be a simple approach for gaining information about transcapillary heat transport in the interior of the lung and about transit times from the pulmonary artery to the air space as well as from there to the left atrium. Our method may be helpful in furthering information about pulmonary capillary blood flow received from in vivo microscopy on the surface of the lung [2-4]. This is of particular interest since pulmonary blood flow is heterogeneous and not only increases in dependent lung regions [5] but also has a hilar-to-peripheral gradient [6]. In addition, subpleural capillaries have different diameters when compared to interior capillaries [7], so that it is likely that capillary blood flow and mean transit times on 
the surface of the lung do not automatically represent blood flow within the interior of the lung.

The present results were obtained from isolated rabbit lungs perfused with their own blood. The main advantage of this experimental protocol is the exact and independent control of study conditions, especially of pulmonary blood flow as the major variable for mean transit times. In addition, isolated lungs allow the systematic study of various bronchial and extrabronchial registration sites, for instance on the surface and between the lobes of the lungs. We found that typical temperature-time curves can only be recorded within the bronchial system and when the thermistor is advanced into the wedge position in the bronchial periphery. Since isolated lungs have no bronchial circulation, effects of systemic blood flow via bronchial arteries can be excluded so that all temperature changes of the bronchial thermistor can be attributed to changes in blood temperature of the pulmonary vessels. In vivo, the bronchial circulation communicates with pulmonary alveolar microvessels $[8,9]$. If the bronchial circulation were to affect the bronchial temperature signal, a marked delay would be expected. However, from preliminary observations in dogs [10] it appears that systemic bronchial blood changes neither the shape of the bronchial signal nor the resulting mean transit times in a relevant fashion when compared to the results in isolated lungs. Thus, the bronchial circulation appears to play no important role for the bronchial temperature signal.

In the present experiments, the lungs were ventilated ex situ with positive pressures. We cannot exclude the possibility that negative pleural pressure influences the recorded bronchial signals, possibly by altering left-atrial and pulmonary arterial pressures. A further limitation relates to the position of the head of the bronchial thermistor. This head (diameter $0.46 \mathrm{~mm}$ ) could, theoretically, have caused changes in the regional ventilation pattern. However, hypoxic pulmonary vasoconstriction with subsequent changes in regional perfusion is unlikely because this response is not only a function of alveolar oxygen tension but also of mixed venous oxygen tension [11], which should have been constant.

The major finding of the present study was that after injection of cold solutions into the pulmonary artery of isolated rabbit lungs, temperature-time curves can be recorded in their distal airways. We conclude that these bronchial curves represent transcapillary heat transport and that bronchial temperature reflects mainly temperature changes of the capillary bed and of small pre- and postcapillary vessels. Numerous small vessels in close proximity to the terminal airways contribute to this bronchial signal depending on capillary dispersion as well as diffusion properties between the vessels and the terminal bronchial wall. Although some larger extracapillary vessels or changes in air temperature could also contribute to the bronchial signal, the majority of it relates to the capillary bed and to small pre- and postcapillary vessels in close proximity of the bronchioli. The bronchial system which is surrounded by the alveolar/capillary space, favours an effective heat exchange between the lung tissues and the capillary bed. The conditions for diffusion of cold from the capillary bed to the bronchial thermistor are optimal because of the short distance from the vascular bed to the thermistor, the large total vessel surface, and the low flow rate with correspondingly prolonged contact times.
Since we studied the distal airways as an approach to the pulmonary capillary bed, a signal with excellent extravascular access had to be used. Cold appeared to be a good choice because it yields an easily detectable signal from the intravascular as well as the intrabronchial thermistors with a significant transfer of indicator to the bronchial space $[1,10]$. In addition, it allowed frequent determinations since there was no recirculation due to temperature regulation of the perfusate with a warm water bath. In pilot studies in isolated lungs we also attempted to record concentration-time curves after dye injection (indocyanine green) with the help of intrabronchial fibreoptic catheters. We hoped to use the dye-based calculations of mean transit times for determination of pre- and postcapillary intravascular volumes $[12,13]$. However, we found it impossible to obtain bronchial dye-dilution curves in normal lungs. Only with gross intra-alveolar oedema could bronchial dye-signals be observed. In contrast, cold-based calculations of mean transit times measure the whole thermal volume including intravascular and extravascular lung water as well as further extravascular structures $[14,15]$. After one pass through the pulmonary circulation almost all cold is recovered $[16,17]$. One aspect to be considered in this context is that thermal volume changes with formation of oedema. While we found a similar distribution of pre- and postbronchial mean transit times in the present experiments, where none of the eight lungs developed signs of oedema, the distribution of pre- and postcapillary mean transit times might be different with oedema formation.

The bronchial mean transit times may be used to divide transpulmonary transit times into two parts, from the pulmonary artery to the bronchial system and from there to the left atrium. Since we recorded changes in total thermal energy of numerous capillaries in close proximity to the distal bronchial system with the bronchial thermistor outside of the vascular system, two assumptions were made: 1) the tracer is distributed uniformly in the capillary system; and 2) the distal bronchial temperature reflects the capillary temperature without significant delay or loss of tracer. Under these conditions the bronchial temperaturetime curve should mirror a summarized capillary curve, allowing an estimation of mean transit times. However, regardless of these limitations for the calculation of the bronchial mean transit times, bronchial appearance times and times to peak were also always located between the pulmonary arterial and left atrial ones, and the shapes of the bronchial curves conformed to dilution curves, so that the capillary-bronchial unit does indeed appear to behave like a single unit.

Pulmonary blood flow is a major variable of pulmonary mean transit times determining the time period for oxygenation of erythrocytes within the capillary bed. With increasing flow rate from 50 to $200 \mathrm{~mL} \cdot \mathrm{min}^{-1}$, prebronchial transit times decreased from 4.6 to $2.2 \mathrm{~s}$ and postbronchial transit times from 5.2 to $1.8 \mathrm{~s}$. At the same time, the corresponding thermal volumes increased from 3.8 to $7.3 \mathrm{~mL}$ (prebronchial) and 4.3 to $6.0 \mathrm{~mL}$ (postbronchial). Why the relative increase in prebronchial volume $(+92 \%)$ is larger than the increase in postbronchial volume $(+39 \%)$ cannot be answered by our experiments.

In summary, we found that in isolated blood perfused rabbit lungs, bronchial temperature-time curves after injection of cold solutions into the pulmonary artery were 
interspaced between those recorded in the pulmonary artery and the left atrium. Regardless of blood flow preand postbronchial mean transit times were approximately equal. We conclude that bronchial temperature is a simple approach to the pulmonary capillary bed that might be helpful to gain further information about transcapillary transport functions of the interior of the lung.

\section{References}

1. Vliers ACAP, Oeseburg B, Visser KR, Zijlstra WG. Choice of detection site for the determination of cardiac output by the thermal dilution: the injection-thermistor catheter. Cardiovasc Res 1973; 7: 133-138.

2. Capen RL, Latham LP, Wagner WW. Comparison of direct and indirect measurements of pulmonary capillary transit times. J Appl Physiol 1987; 62: 1150-1154.

3. Ayappa I, Brown LV, Wang PM, Lai-Fook SJ. Arterial, capillary, and venous transit times and dispersion measured in isolated rabbit lungs. J Appl Physiol 1995; 79: 261-269.

4. Dawson CA, Capen RL, Latham LP, et al. Pulmonary arterial transit times. J Appl Physiol 1987; 63: 770-777.

5. West JB, Dollery CT, Naimark A. Distribution of blood flow in isolated lung; relation to vascular and alveolar pressures. J Appl Physiol 1964; 19: 713-724.

6. Walther SM, Domino KB, Glenny RW, Polissar NL, Hlastala MP. Pulmonary blood flow distribution has a hilar-to-peripheral gradient in awake, prone sheep. $J$ Appl Physiol 1997; 82: 678-685.

7. Short AC, Montoya ML, Gebb SA, Presson RG, Wagner WW, Capen RL. Pulmonary capillary diameters and recru- itment characteristics in subpleural and interior networks. J Appl Physiol 1996; 80: 1568-1573.

8. Wagenvoort CA, Wagenvoort N. Arterial anastomoses, bronchopulmonary arteries, and pulmobronchial arteries in perinatal lungs. Lab Invest 1967; 16: 13-24.

9. Deffebach ME, Charan NB, Lakshminarayan S, Butler J. The bronchial circulation: small, but a vital attribute of the lung. Am Rev Respir Dis 1987; 135: 463-481.

10. Loer SA, Scheeren TWL, Arndt JO. Bronchial temperature as a key to the interior pulmonary capillary bed of anaesthetized dogs. Intensive Care Med 1997; 23: 951954.

11. Marshall C, Marshall BE. Site and sensitivity for stimulation of hypoxic pulmonary vasoconstriction. J Appl Physiol 1983; 55: 711-716.

12. Dow P. Estimation of cardiac output and central blood volume by dye dilution. Physiol Rev 1956; 36: 77-102.

13. Newman EV, Merrell M, Genecin A, Monge C, Milnor WR, McKeever WP. The dye dilution method for describing the central circulation. Circulation 1951; 6: 735746

14. Effros RM. Lung water measurements with the mean transit time approach. J Appl Physiol 1985; 59: 673-683.

15. Chinard FP, Enns T, Nolan MF. Pulmonary extravascular water volumes from transit time and slope data. J Appl Physiol 1962; 17: 179-183.

16. Arfors KE, Malmberg P, Pavek K. Conservation of thermal indicator in lung circulation. Cardiovasc Res 1971; 5: 530-534.

17. Böck J, Deuflhard P, Hoeft A, et al. Thermal recovery after passage of the pulmonary circulation assessed by deconvolution. J Appl Physiol 1988; 64: 1210-1216. 